OnLine Journal of Biological Sciences 11 (2): 70-75, 2011

ISSN 1608-4217

(C) 2011 K.B.K. Mohan et al., This open access article is distributed under a Creative Commons Attribution

(CC-BY) 3.0 license

\title{
Relationship of Body Composition Parameters with Hip and Fore Arm Bone Mineral Density: An Indian Perspective
}

\author{
K.B. Kishore Mohan, V. Sapthagirivasan and M. Anburajan \\ Department of Bio-Medical Engineering, \\ SRM University, Kattankulathur, 603203, Tamilnadu, India
}

\begin{abstract}
Problem statement: The relationship between obesity and osteoporosis has been widely studied and epidemiological evidence shows that obesity is correlated with increased bone mass. Anthropometric factors such as body height and body weight which are related to body mass index should be considered. Approach: We measured whole body fat mass, fat free mass, muscle mass, Body water, percentage fat mass and body mass index in the South Indian women $(\mathrm{n}=178$, age $=38.34 \pm 13.59)$ by slim manager N-40 (Body Composition Analyzer, Korea). Bone mineral density was measured at right proximal femoral region of 50 South Indian women $(n=50$, age $=50.12 \pm 13.73)$ using the device DPX Prodigy DXA Scanner, GELunar, USA. Similarly, Bone mineral density of fore arm was measured using peripheral dual energy x-ray absorptiometry (Osteometer, DTX-200 Ameritech Inc, USA) for 62 (39.76 \pm 13.41$)$ women. Results: Body composition parameters such as body water, muscle mass, fat mass and fat free mass exhibited high significance with weight $(\mathrm{p}<0.001)$. Trochanter BMD demonstrated high significance with body water, fatfree mass and muscle mass $(\mathrm{p}<0.01)$. BMI displayed high significance with body fat mass $(\mathrm{p}<0.0001)$. Conclusion: So conclusion of this study depicts that the body composition parameters exhibited significant correlation with right femoral bone mineral density measured at various anatomical sites, but demonstrated no correlation with right fore arm bone mineral density, similarly measured at anatomical sites.
\end{abstract}

Key words: Osteoporosis, body mass index, Dual energy X-ray Absorptiometry (DXA), fat mass, fat free mass, body composition, Bone Mineral Density (BMD), Bone Mass (BM)

\section{INTRODUCTION}

'Osteoporosis' is the pathological situation, characterized by a bunch of irregularities such as bone thinning and decrementation in micro-architecture, that would lead to increased risk of fracture (Kamaran et al., 2010). Out of the total Indian population, approximately $5.5 \%$ people are osteoporotic $0.2 \%$ people are being added every year. One among three women and one among eight men are suffering from osteoporotic bone fracture in India (International Osteoporosis Foundation, 2011). Non traumatic skeletal fracture is directly related to decreased bone mass and is the major characteristic of osteoporosis. Most of the fractures occur in people, who might not possess osteoporosis. This condition would be defined by areal BMD (Yahtyng et al., 2011). Osteoporosis occurs primarily as a result of normal ageing, but it can arise as a result of impaired development of peak bone mass due to delayed puberty or excessive bone loss during adulthood due to estrogen deficiency in women, under nutrition, or corticosteroid use. Hip fractures are the most serious, as they more often result in hospitalization. Research has identified a number of risks that make it more likely for one individual over another to get osteoporosis. More number of research studies has demonstrated that Bone Mineral Density (BMD) correlates well with the strength of the bone and hence it predicts the future risk of bone fracture. Premature deaths are often evidenced with osteoporotic fractures. Hence osteoporosis medication would help a long way in battling mortality risks in women and men. (Center et al., 2011). When percent body fat and percent truck fat are compared with BMD among chinese, black and white subjects, ethnic difference was witnessed. Chinese subjects possessed comparatively higher BMD than black and white subjects who had huge body structure and trunk fat (Lu et al., 2011). Studies show that bone loss can be reversed by pregnancy and breast feeding. Breast feeding controls changes in fat mass that can be reversed (Moller et al., 2011). Decreae in bone mineral content is strongly correlated with birth weight. Increased fracture risk was directly proportional to bone mineral content (Schlussel et al., 2010). By proper maintenance of weight, hip geometric strength can be retained and hip fracture can

Corresponding Author: K.B. Kishore Mohan, Department of Bio-medical Engineering, SRM University, Kattankulathur, 603203, Tamilnadu, India 
be reduced as well (Dongmei et al., 2011). New model incorporating the normal values of BMD in children has been innovated, taking into consideration: weight, height, percent body fat and sexual maturity in addition to old parameters such as age, gender and race (Short $e t$ al., 2011). Recent studies witness the fact of being, Adiponectin, as a risk factor of bone loss in women, but not Leptin (Barbour et al., 2011). Histomorphometric study on trabecular bone in osteoporotic sheep displayed the reduction in bone volume, osteoid surface area, bone formation rate and osteocyte density. On the contrary, there was increment in eroded surface and empty lacunoe density. There was correlation between chages in osteocyte density and osteoblast as well as osteoclast cavity (Zarrinkalam et al., 2011). DXA has been used to measure macroscopic changes in BM at the proximal femur that correlate with hip fracture risk. Anthropometric factors such as body-height and bodyweight which are related to Body Mass Index (BMI) are considered. Obesity is one of the major constraints in health care industries. The possession of BMI of 25.0 to 29.9 is regarded to be overweight. BMI, higher than 30.0 has been refered as obesity. The prevalence of obesity didn't seem to be continueing at the same pace over the past decade, especially for women and perhaps for men (Flegal et al., 2010).

In the present study, we investigated the association of $\mathrm{BM}$ in right proximal femur and fore arm with respect to FM and FFM in pre and post menopausal women and estimated the risk of higher percentage FM on osteoporosis, osteopenia and normal groups.

\section{MATERIALS AND METHODS}

Study population: This study was a part of experimental investigation related to public health. A free medical camp for obesity and osteoporosis was conducted at SRM Hospital and Medical Research center Chennai during the month of July to August 2010. A total number of $234(\mathrm{n}=234$, age $=$ $37.69 \pm 14.08)$ Indian subjects participated in this study. $156(\mathrm{n}=156$, age $=36.95 \pm 14.67)$ men and $178(\mathrm{n}=$ 178 , age $=38.34 \pm 13.59$ ) women (pre menopausal and post menopausal) whose age ranged from 20-85 years were included in the current study. Participants with known kidney diseases, chronic liver, hypo-and hyperthyroids and malignancy were excluded. We have taken in to consideration, only the female population in this study, though male population also participated.

Measurement of bone mineral content, BMD and body composition: Bone Mineral Content (BMC) and $\mathrm{BMD}$ of the right proximal femur were measured by using a dual energy X-ray Absorptiometry (DXA), the
Total Body Bone Densitometer (DPX Prodigy DXA Scanner, GE-Lunar, USA). It measures BMD at different regions of the proximal femur regions, which includes neck, Ward's triangle, trochanter region (greater and lower), shaft cortex and total proximal femur. The measured BMD $\left(\mathrm{g} \mathrm{cm}^{-2}\right)$ at these Regions Of Interest (ROI) were denoted as follows: N-BMD, W-BMD, Tr-BMD, S-BMD and T-BMD. Similarly, $\mathrm{BMC}$ and BMD of fore arm were measured using peripheral DXA (Osteometer, DTX-200 Ameritech Inc, Hawthorn, California, USA). Lastly FM and FFM were measured using the body composition analyzer (Slim manager, N40, AIIA Communications Inc, South Korea). Whole-body fat mass and fat free mass were expressed in terms of weight $(\mathrm{kg})$ and as a percentage of body weight. WHO's diagnostic criteria for osteoporosis was used in the study; Based on the femur neck BMD values measured by DXA, total women were divided into the following sub-groups: Group-I: Normal Indian women (T-score $>-1$ ); Group-II: Indian women with osteopenia $(-2.5<\mathrm{T}$-score $<-1)$; and GroupIII: Indian women with osteoporosis (T-score <-2.5), but no previously known osteoporotic fractures.

Anthropometric measurements: Each participant underwent general physical examination pertaining to height and weight measurement in meters and kilograms respectively in order to acquire BMI. Care was taken to maintain height proximity to be $0.1 \mathrm{~cm}$ on a studio meter and weight proximity to be $0.1 \mathrm{~kg}$ with the subject positioned motionless in the center of the weighing scale. None of the subjects wore shoes or any other foot wears, while the measurements were taken.

Data analyses: The data was analyzed using SPSS software package version 10.0 (SPSS Inc., Chicago, USA) and Micro-soft Excel version 2007 (MS-Office package, Microsoft Inc., Redmond, USA). There was a separate analysis as regards to test items and questionnaire items in the initial phase. Participants were divided into pre and post-menopausal women. Menopausal status is the main predictor of bone mass and BMD. Henceforth, menopausal status is the major criterion in determining osteoporosis and osteopenia.

\section{RESULTS}

Out of 178 women who possessed mean age $( \pm \mathrm{SD})$ of $38.34( \pm 13.59), 62(34.85 \%)$ agreed to undergo forearm peripheral DXA (p-DXA) test who had $39.76( \pm 13.41)$ as their mean age and 50 (28.09\%) agreed to take-up femoral DXA test who had $50.02( \pm 13.28)$ as their mean age. 
OnLine J. Biol. Sci., 11 (2): 70-75, 2011

Table 1: Demographic information of females participated

\begin{tabular}{lcc}
\hline Characteristics & Mean \pm SD & Range \\
\hline Age $($ Years $)$ & $45.6 \pm 14.7$ & $25.0-70.0$ \\
Height $(\mathrm{Cm})$ & $150.8 \pm 6.0$ & $142-161$ \\
Weight $(\mathrm{Kg})$ & $53.6 \pm 9.7$ & $40.0-72.0$ \\
BMI $\left(\mathrm{kg} \mathrm{m}^{-2}\right)$ & $23.5 \pm 3.5$ & $18.8-30.8$ \\
\hline
\end{tabular}

Table 2: Body composition analysis

\begin{tabular}{lcc}
\hline Characteristics & Mean \pm S D & Range \\
\hline Protein $(\mathrm{Kg})$ & $7.8 \pm 2.3$ & $5.0-13.0$ \\
Mineral $(\mathrm{Kg})$ & $2.6 \pm 0.8$ & $1.7-4.4$ \\
BFM $(\mathrm{Kg})$ & $21.5 \pm 5.8$ & $12.4-34$ \\
BW $(\mathrm{Lt})$ & $23 \pm 3.5$ & $17.9-28.8$ \\
MM $(\mathrm{Kg})$ & $29.3 \pm 4.4$ & $22.8-36.6$ \\
FFM $(\mathrm{Kg})$ & $31.5 \pm 4.7$ & $24.5-39.3$ \\
PBF $(\%)$ & $40.1 \pm 6.0$ & $30.5-52.0$ \\
\hline
\end{tabular}

Table 3: Right femur bone mineral content

\begin{tabular}{lrr}
\hline Characteristics & Mean \pm SD & Range \\
\hline N-BMD $\left(\mathrm{g} \mathrm{cm}^{-2}\right)$ & $0.86 \pm 0.18$ & $0.7-0.4$ \\
W-BMD $\left(\mathrm{g} \mathrm{cm}^{-2}\right)$ & $0.68 \pm 0.23$ & $0.4-1.4$ \\
Tr-BMD $\left(\mathrm{g} \mathrm{cm}^{-2}\right)$ & $0.69 \pm 0.15$ & $0.5-1.1$ \\
S-BMD $\left(\mathrm{g} \mathrm{cm}^{-2}\right)$ & $0.98 \pm 0.33$ & $0.6-1.6$ \\
T-BMD $\left(\mathrm{g} \mathrm{cm}^{-2}\right)$ & $0.88 \pm 0.19$ & $0.6-1.4$ \\
T.T-score & $-1.05 \pm 1.52$ & $-3.3-2.9$ \\
\hline
\end{tabular}

Table 4: Right for arm bone mineral content

\begin{tabular}{lll}
\hline Characteristics & Mean \pm SD & Range \\
\hline DT-BMD $\left(\mathrm{g} \mathrm{cm}^{-2}\right)$ & $0.33 \pm 0.1$ & $0.01-0.44$ \\
R-BMD $\left(\mathrm{g} \mathrm{cm}^{-2}\right)$ & $0.33 \pm 0.11$ & $0.03-0.46$ \\
U-BMD $\left(\mathrm{g} \mathrm{cm}^{-2}\right)$ & $0.33 \pm 0.09$ & $0.06-0.41$ \\
N-Roi BMD $\left(\mathrm{g} \mathrm{cm}^{-2}\right)$ & $0.31 \pm 0.01$ & $0.13-0.56$ \\
\hline
\end{tabular}

Table 5: Demographic information of females' participated-group wise analysis

\begin{tabular}{|c|c|c|c|c|}
\hline \multirow[b]{2}{*}{ Characteristics } & \multicolumn{4}{|l|}{ Mean \pm SD } \\
\hline & Group-I & Group-II & Group-III & Significance \\
\hline Age (Years) & $40.6 \pm 13.4$ & $46.7 \pm 14.7$ & $62.0 \pm 11.3$ & $\mathrm{~S}$ \\
\hline Height (Cm) & $151.8 \pm 6.60$ & $150.0 \pm 6.30$ & $149.5 \pm 4.90$ & S \\
\hline Weight (Kg) & $58.5 \pm 9.00$ & $49.8 \pm 8.50$ & $45.0 \pm 7.10$ & S \\
\hline BMI $\left(\mathrm{kg} / \mathrm{m}^{2}\right)$ & $25.3 \pm 3.10$ & $22.1 \pm 3.10$ & $20.1 \pm 1.80$ & S \\
\hline \multicolumn{5}{|c|}{ Body composition analysis } \\
\hline Protein $(\mathrm{Kg})$ & $8.2 \pm 2.5$ & $6.8 \pm 1.7$ & $9.1 \pm 2.90$ & NS \\
\hline Mineral (Kg) & $2.8 \pm 0.8$ & $2.3 \pm 0.6$ & $3.1 \pm 1.00$ & NS \\
\hline BFM (Kg) & $23.9 \pm 5.6$ & $18.7 \pm 3.8$ & $20.3 \pm 11.1$ & LS \\
\hline $\mathrm{BW}(\mathrm{Lt})$ & $24.4 \pm 4.0$ & $21.7 \pm 2.4$ & $21.7 \pm 3.30$ & LS \\
\hline $\mathrm{MM}(\mathrm{Kg})$ & $31.0 \pm 5.1$ & $27.7 \pm 3.1$ & $27.6 \pm 4.20$ & LS \\
\hline FFM (Kg) & $33.3 \pm 5.4$ & $29.7 \pm 3.3$ & $29.6 \pm 4.50$ & LS \\
\hline $\operatorname{PBF}(\%)$ & $41.6 \pm 6.0$ & $38.5 \pm 5.5$ & $39.1 \pm 10.0$ & LS \\
\hline \multicolumn{5}{|c|}{ Right femur bone mineral content } \\
\hline $\mathrm{N}-\mathrm{BMD}\left(\mathrm{g} \mathrm{cm}^{-2}\right)$ & $0.981 \pm 0.19$ & $0.773 \pm 0.04$ & $0.667 \pm 0.01$ & S \\
\hline W-BMD $\left(\mathrm{g} \mathrm{cm}^{-2}\right)$ & $0.827 \pm 0.25$ & $0.571 \pm 0.06$ & $0.454 \pm 0.02$ & S \\
\hline $\operatorname{Tr}-\mathrm{BMD}\left(\mathrm{g} \mathrm{cm}^{-2}\right)$ & $0.796 \pm 0.13$ & $0.593 \pm 0.06$ & $0.535 \pm 0.01$ & S \\
\hline S-BMD $\left(\mathrm{g} \mathrm{cm}^{-2}\right)$ & $1.201 \pm 0.10$ & $0.893 \pm 0.10$ & $0.702 \pm 0.12$ & S \\
\hline T-BMD $\left(\mathrm{g} \mathrm{cm}^{-2}\right)$ & $1.013 \pm 0.16$ & $0.776 \pm 0.08$ & $8 \quad 0.625 \pm 0.04$ & S \\
\hline T.T- score & $0.50 \pm 1.250$ & $-1.85 \pm 0.670$ & $0-3.05 \pm 0.35$ & S \\
\hline \multicolumn{5}{|c|}{ Right fore arm bone mineral content } \\
\hline DT-BMD $\left(\mathrm{g} \mathrm{cm}^{-2}\right)$ & $0.351 \pm 0.05$ & $0.333 \pm 0.05$ & $0.221 \pm 0.30$ & $\mathrm{~S}$ \\
\hline R-BMD $\left(\mathrm{g} \mathrm{cm}^{-2}\right)$ & $0.364 \pm 0.06$ & $0.325 \pm 0.09$ & $0.247 \pm 0.30$ & $\mathrm{~S}$ \\
\hline U-BMD $\left(\mathrm{g} \mathrm{cm}^{-2}\right)$ & $0.339 \pm 0.05$ & $0.345 \pm 0.06$ & $0.230 \pm 0.24$ & NS \\
\hline N-Roi BMD $\left(\mathrm{g} \mathrm{cm}^{-2}\right)$ & $0.319 \pm 0.04$ & $0.333 \pm 0.13$ & $0.245 \pm 0.17$ & NS \\
\hline
\end{tabular}

Overall, 34 (19.10\%) women who participated in all the tests were with the mean age of $45.56( \pm 14.65)$. Participants fall under the following categorization with respect to different obesity groups; Underweight $2 \%$, normal $58 \%$, overweight $30 \%$ and obese $10 \%$. That is the obese category was having $49 \%((10-6.7) / 6.7 * 100)$ higher than adolescent girls. Nutrition oriented education has to be incorporated in schools to promote nutrion acquirement. This is to overcome the hazardous effects which occur by nutrition defficiency, perticularly in adolescents. Obese and overweight adolescents consumed less proportions of carbohydrates, protenis, thiamins subjects who were dieting, consumed signficant debile amounts of protein, carbohydrates, thiamin as well (Bidad et al., 2008). Femur neck BMD obtained in normal group was $0.85\left(\mathrm{~g} \mathrm{~cm}^{-2}\right)$ and for obese group it was 0.925 $\left(\mathrm{g} \mathrm{cm}^{-2}\right)$. The increment percentage found was 13 and $17.5 \%$ for normal and obese participants respectively when compared to Iranian population (Meybodi et al., 2011). The overall weighted prevalence of obese women was $35 \%$ that is $45 \%$ higher than the Iranian women population (Navadeh et al., 2011). Table 1 categorizes the demographic information of the female participants who participated in all the tests. Their age was between twenty five to seventy years. Average BMI value observed was $23.5( \pm 3.5)$ and it ranged from 18.8-30.8 which signifies the fact that the participants ranged from normal to obese category. Table 2 exhibits range (min-max) of body composition characteristics. Muscle Mass (MM) had 29.3 $( \pm 4.4)$ as its mean value; $22.8-36.6$, being its range. The dominance of fat free mass and body water compared to fat mass, as well as higher muscle mass signifies the muscular nature of the participant population.

Total T-Score of the characteristics of right femoral bone mineral content was found to be $-1.05( \pm 1.52)$ and its range being -3.3 to -2.9 as shown in Table 3. Also, BMD with respect to shaft is found to be highest. Table 4 depicts almost same mean value with respect to DTBMD, R-BMD and U-BMD of right for arm bone mineral content. But there is a deviation in the mean value of N-Roi BMD. High variation was observed in the range of all the characteristics. Table 5 categorizes the significances of characteristics such as age, height, weight, BMI on the basis of group-wise analysis (i.e., Group-I, Group-II, Group-III which were classified on the basis of existence/non-existence of osteoporosis such as normal, osteopenia and osteoporosis). As regards to body composition analysis we found that parameters such as protein, mineral, BFM have not exhibited any significance; body water, MM and FFM exhibited little or moderate significance. 
OnLine J. Biol. Sci., 11 (2): 70-75, 2011

Table 6: Significance between body composition parameters and bone mineral density as well as anthropometric parameters

\begin{tabular}{|c|c|c|c|c|c|c|c|c|c|}
\hline Body composition parameters & Height & Weight & BMI & NBMD & WBMD & Tr-BMD & S-BMD & T-BMD & T.T-score \\
\hline Mineral & $S_{x}$ & NS & NS & NS & NS & NS & NS & NS & NS \\
\hline BFM & NS & $\mathrm{S}_{\mathrm{b}}$ & $\mathrm{S}_{\mathrm{a}}$ & NS & NS & NS & NS & NS & NS \\
\hline Body Water & $\mathrm{S}_{\mathrm{a}}$ & $\mathrm{S}_{\mathrm{b}}$ & NS & $\mathrm{S}_{\mathrm{c}}$ & $\mathrm{S}_{\mathrm{y}}$ & $\mathrm{S}_{\mathrm{c}}$ & $\mathrm{S}_{\mathrm{z}}$ & $\mathrm{S}_{\mathrm{z}}$ & $\mathrm{S}_{\mathrm{z}}$ \\
\hline $\mathrm{MM}$ & $\mathrm{S}_{\mathrm{a}}$ & $\mathrm{S}_{\mathrm{b}}$ & NS & $\mathrm{S}_{\mathrm{c}}$ & $\mathrm{S}_{\mathrm{y}}$ & $S_{d}$ & $\mathrm{~S}_{\mathrm{z}}$ & $\mathrm{S}_{\mathrm{z}}$ & $\mathrm{S}_{\mathrm{z}}$ \\
\hline FFM & $\mathrm{S}_{\mathrm{a}}$ & $S_{\mathrm{b}}$ & NS & $\mathrm{S}_{\mathrm{c}}$ & $\mathrm{S}_{\mathrm{y}}$ & $\mathrm{S}_{\mathrm{c}}$ & $\mathrm{S}_{\mathrm{z}}$ & $\mathrm{S}_{\mathrm{z}}$ & $\mathrm{S}_{\mathrm{z}}$ \\
\hline PBF & NS & NS & $\mathrm{S}_{\mathrm{c}}$ & NS & NS & NS & NS & NS & NS \\
\hline
\end{tabular}

where: $\mathrm{S}_{\mathrm{a}}-\mathrm{p}<0.0001, \mathrm{~S}_{\mathrm{b}}-\mathrm{p}<0.001, \mathrm{~S}_{\mathrm{c}}-\mathrm{p}<0.008, \mathrm{~S}_{\mathrm{d}}-\mathrm{P}<0.01, \mathrm{~S}_{\mathrm{x}}-\mathrm{p}<0.05, \mathrm{~S}_{\mathrm{y}}-\mathrm{p}<0.04, \mathrm{~S}_{\mathrm{z}}-\mathrm{p}<0.02$ and NS-Not Significant

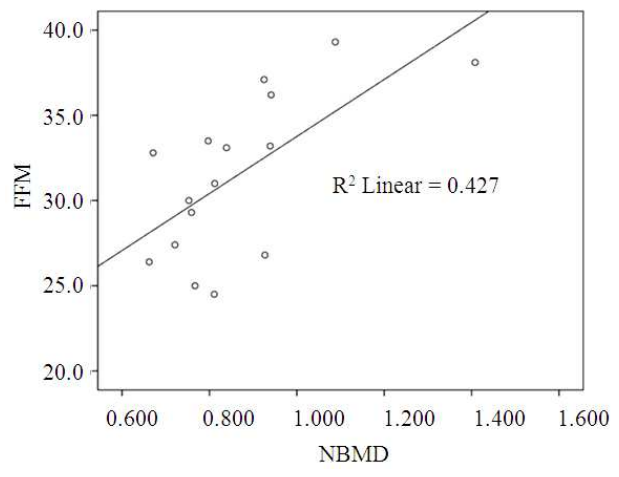

Fig. 1: Plotting of FFM (Kg) Vs N-BMD $\left(\mathrm{g} \mathrm{cm}^{-2}\right)$

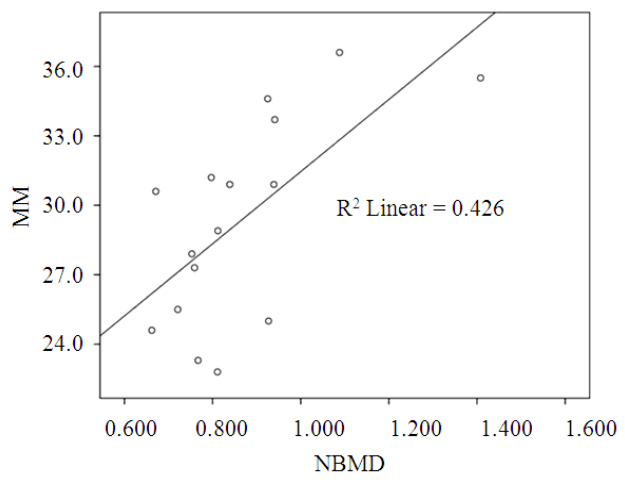

Fig. 2: Plotting of MM (Kg) Vs N-BMD $\left(\mathrm{g} \mathrm{cm}^{-2}\right)$

PBF has shown no significance. As regards to bone mineral content of right femur, almost all parameters such as N-BMD, W-BMD, Tr-BMD, S-BMD, T-BMD and T.T-score have shown significance. Similarly with respect to bone mineral content of right for arm factors such as DT-BMD and R-BMD have exhibited significance, where as U-BMD and N-Roi BMD have shown no significance. We found that, apart from anthropometric characteristics and BMI, right femur BMD characteristics have demonstrated moderate significance as displayed in Table 6 .

Plotting of N-BMD Vs FFM, MM and BW were shown in Fig. 1-3 respectively. Plotting of Tr-BMD Vs BW and FFM were shown in Fig. 4 and 5 respectively. Fig. 6 shows the plot of BFM Vs BMI.

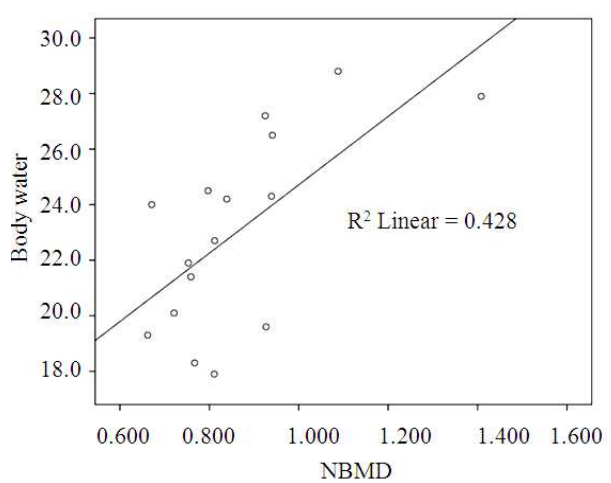

Fig. 3: Plotting of BW (Lt) Vs N-BMD $\left(\mathrm{g} \mathrm{cm}^{-2}\right)$

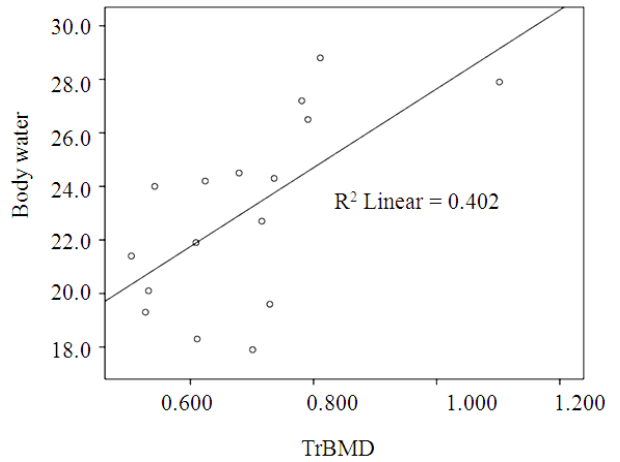

Fig. 4: Plotting of BW (Lt) Vs Tr-BMD $\left(\mathrm{g} \mathrm{cm}^{-2}\right)$

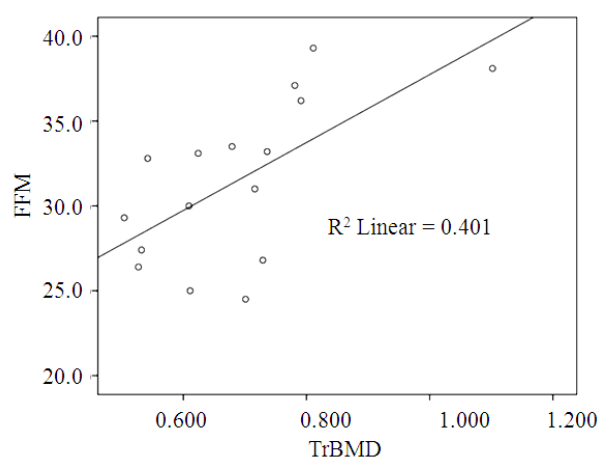

Fig. 5: Plotting of FFM (Kg) Vs Tr-BMD $\left(\mathrm{g} \mathrm{cm}^{-2}\right)$ 
OnLine J. Biol. Sci., 11 (2): 70-75, 2011

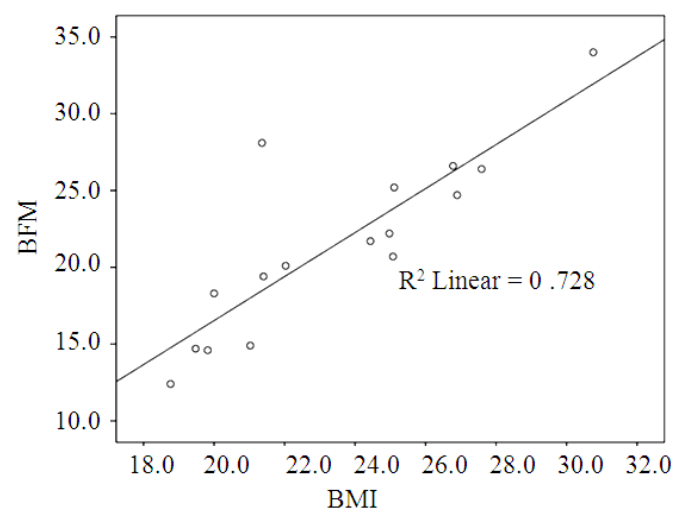

Fig. 6: Plotting of BFM (Kg) Vs BMI $\left(\mathrm{Kg} \mathrm{m}^{-2}\right)$

\section{DISCUSSION}

In this study, it was observed that 47 and $35.29 \%$ of the study Indian women found to posses osteopenia and osteoporosis respectively. Also it was found that there was progressive increment in age from Group-I to Group-III. The increment percentage between Group-I and Group-II, Group-II and Group-III, Group-I and Group-III was 15, 32.7 and $52.7 \%$ respectively. But, when height, weight, BMI was considered, it was noticed that there was progressive decrement from Group-I to Group-III. BMI showed 20.6\% difference, height showed $1.5 \%$ difference and weight showed $23.11 \%$ difference between Group-I and Group-III respectively. This implies the fact that height showed less impact in this study. When the body composition parameters such as MM and FFM are considered, it was noticed that there was decreased percentage between Group-I and Group-II, Group-II and Group-III, Group-I and Group-III such as 10.6, 0.4 and $10.9 \%$ respectively as regards to MM; similarly with respect to FFM the percentages were $10.8,0.3$ and $11.1 \%$ respectively. When we considered right femur bone mineral content we found that the difference between Group-I and Group-III was $38.3 \%$ as regards to T-BMD; similarly while considering right for arm mineral content we deciphered that the difference was $32.2 \%$. N-BMD showed moderate significance $(\mathrm{p}<0.008)$ with body water (Fig. 3), Muscle mass (Fig. 2) and Fat free mass (Fig. 1). W-BMD and S-BMD exhibited lesser significance with BW, MM and FFM ( $<<0.04, \mathrm{p}<0.02$ respectively). T-BMD and T.T-Score similarly demonstrated lesser significance with BW, MM and FFM ( $\mathrm{p}<0.02)$. Tr-BMD showed high significance with BW (Fig. 4), FFM ( $1<0.008)$ shown in Fig. 5 and MM ( $<<0.01)$. Height showed lesser significance with mineral $(\mathrm{p}<0.05)$, high significance with BW, MM and FFM $(\mathrm{p}<0.0001)$. Weight exhibited high significance with BFM, BW, MM and FFM $(\mathrm{p}<0.001)$. BMI displayed high significance with BFM $(\mathrm{p}<0.0001)$ and moderate significance with PBF $(\mathrm{p}<0.008)$.

\section{CONCLUSION}

In conclusion, we conclude that the body composition parameters such as Body Water (BW), fat Free Mass (FFM) and Muscle Mass (MM) were exhibited significant correlation with femoral bone mineral content measured at various sites such as trochanter, shaft, neck, total femur and ward's triangle. Anthropometric parameters such as height, weight and calculated BMI also demonstrated significant correlation with body composition parameters. Fore arm bone mineral content measured at sites such as distal total, radius, ulna and New-ROI exhibited no correlation with body composition parameters. Trochanter BMD compared to BMD's measured at other sites in femur region shown, highly significant correlation with body composition parameters.

Authorship and contributorship: Basic concept, theme as well as total study drafting has been contributed by first two authors: Kishoremohan, Sapthagirivasan; whereas, statistical analysis and correlated graphs were performed by Sapthagirivasan and Anburajan made the necessary corrections before uploading the article; provided the idea and guidelines to execute study.

Competing interests: The authors declare no conflict of interests.

\section{ACKNOWLEDGEMENT}

The researchers wish to thank the health care authorities of SRM Hospital for providing space to conduct the camp. They also wish to thank Mrs. Snehalatha, Asst. Proff and final year M. Tech students of biomedical engineering, SRM University for their kind support and help. All costs and related expenditures have been managed by main corresponding author only.

\section{REFERENCES}

Barbour, K.E., J.M. Zmuda, R. Boudreau, E.S. Strotmeyer and M.J. Horwitz et al., 2011. The effects of adiponectin and leptin on changes in bone mineral density. Osteoporos Int. DOI: 10.1007/s00198-011-1768-x 
Bidad, K., S. Anari, S. Tavasoli, L. Nazehi and N. Gholami et al., 2008. Dietary intakes of adolescent girls in relation to weight status. Iran J. Publ. Health, 37: 114-118.

Center, J.R., D. Bliuc, N.D. Nguyen, T.V. Nguyen and J.A. Eisman, 2011. Osteoporosis medication and reduced mortality risk in elderly women and men. J. Clin. Endocrinol. Metab. DOI: 10.1210/jc.2010-2730

Dongmei, N., M. Iki, J. Tamaki, Y. Sato and S. Kagamimori et al., 2011. Association between weight changes and changes in hip geometric indices in the Japanese female population during 10-year follow-up: Japanese Population-based Osteoporosis (JPOS) cohort study. Osteoporos Int. PMID: 21811865

Flegal, K.M., M.D. Carroll, C.L. Ogden and L.R. Curtin, 2010. Prevalence and trends in obesity among US adults, 1999-2008. JAMA, 303: 235241. DOI: 10.1001/jama.2009.2014

International Osteoporosis Foundation, 2011. Facts and statistics about osteoporosis and its impact.

Kamaran, K., R. Ibrahim, M.Z. AbuBakar, T.A. Ibrahim and K. Kaveh et al., 2010. Osteoporosis induction in animal model. Am. J. Anim. Vet. Sci., 5: 139-145. DOI: 10.3844/ajavsp.2010.139.145

Lu, H., X. Fu, X. Ma, Z. Wu and W. He et al., 2011. Relationships of percent body fat and percent trunk fat with bone mineral density among Chinese, black, and white subjects. Osteoporos Int. DOI: 10.1007/s00198-010-1522-9

Meybodi, H.R.A., M. Hemmat-Abadi, R. Heshmat, M.R. Homani and S. Madani et al., 2011. Association between anthropometric measures and bone mineral density: Population based study. Iran J. Publ. Health, 40: 18-24.
Moller, U.K., S.V Streym, L. Mosekilde and L. Rejnmark, 2011. Changes in bone mineral density and body composition during pregnancy and postpartum. A controlled cohort study. Osteoporos Int. PMID: 21607805

Navadeh, S., L. Sajadi, A. Mirzazadeh, F. Asgari and M. Haghazali, 2011. Housewives' obesity determinant factors in Iran; national surveystepwise approach to surveillance. Iran J. Publ. Health, 40: 87-95.

Schlussel, M.M., J.D.S. Vaz and G. Kac, 2010. Birth weight and adult bone mass: A systematic literature review. Osteoporos Int., 21: 1981-91. PMID: 20419292

Short, D.F., B.S. Zemel, V. Gilsanz, H.J. Kalkwarf, J.M. Lappe et al., 2011. Fitting of bone mineral density with consideration of anthropometric parameters. Osteoporos Int., 22: 1047-1057. DOI: 10.1007/s00198-010-1284-4

Yahtyng, S., J.M. Zmuda, R.M. Boudreau, M.A. Petit and K.E. Ensrud et al., 2011. Bone strength measured by peripheral quantitative computed tomography and the risk of nonvertebral fractures: The osteoporotic fractures in men (MrOS) study. J. Bone Mineral Res., 26: 63-71. DOI: 10.1002/jbmr.172

Zarrinkalam, M.R., A. Mulaibrahimovic, G.J. Atkins and R.J. Moore, 2011. Changes in osteocyte density correspond with changes in osteoblast and osteoclast activity in an osteoporotic sheep model. Osteoporos Int. PMID: 21626447 